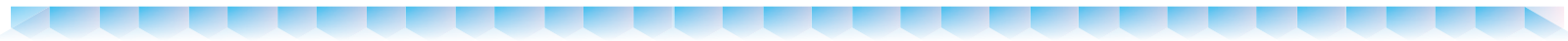


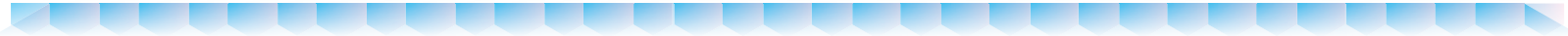
$+2$

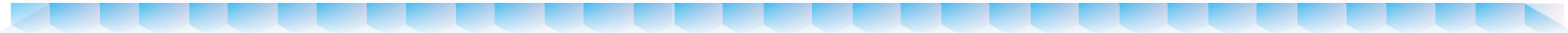

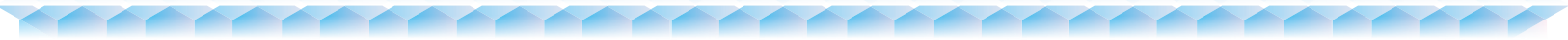

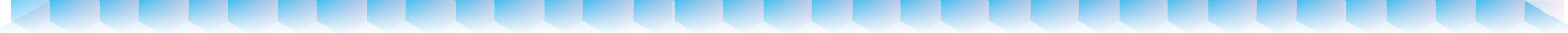

4h
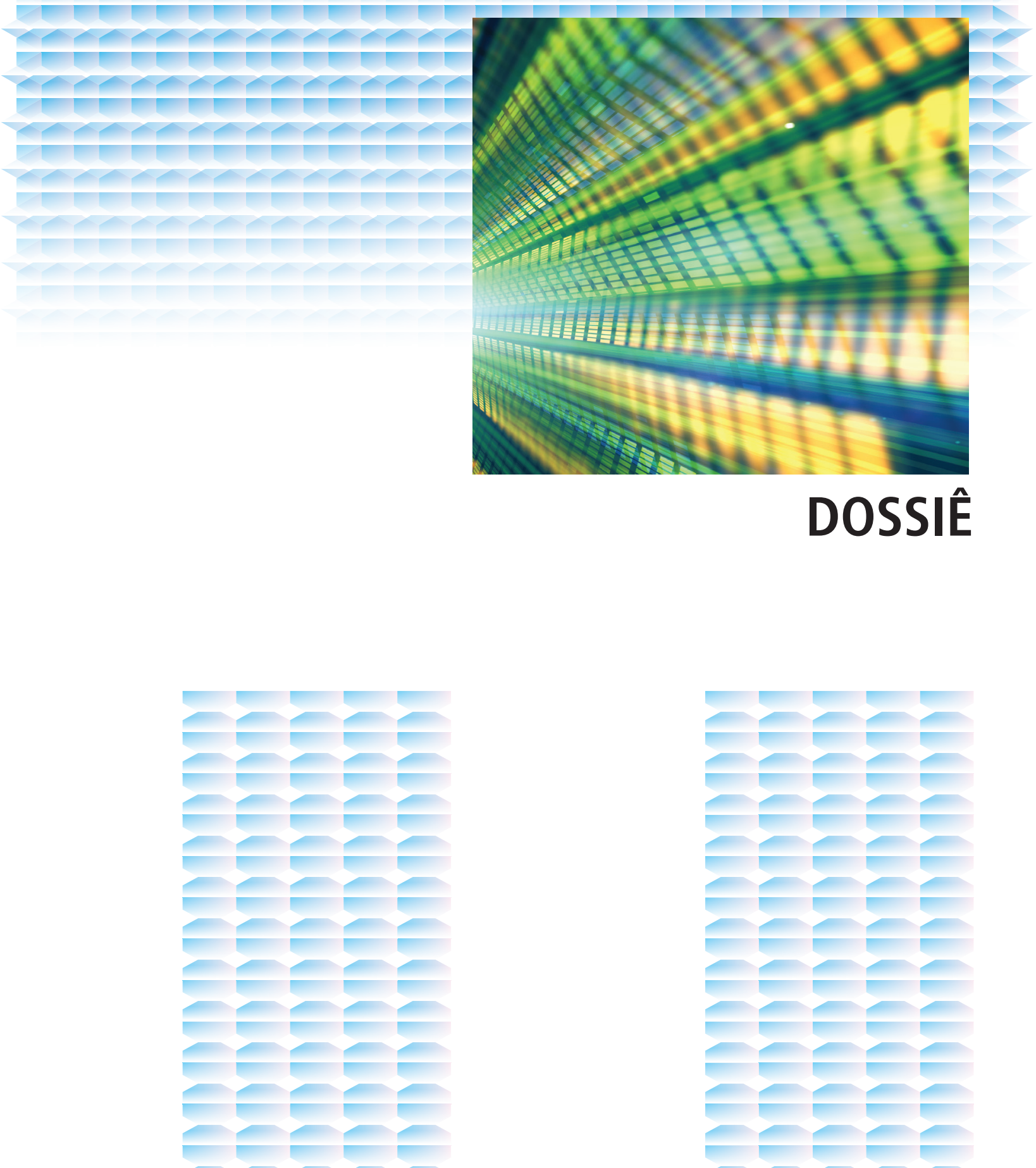



\title{
Inteligência artificial baseada em dados e as operações do capital
}

\author{
Data-based artificial intelligence and capital operations \\ Inteligencia artificial basada en datos y operaciones de capital
}

Sérgio Amadeu da Silveira

UFABC

<sergio.amadeu@ufabc.edu.br>

\section{Resumo}

0 objetivo deste texto é caracterizar 0 intenso cenário de digitalização e sua relação com o capitalismo. Discute as definições de capitalismo informacional, digital, baseado em dados, de vigilância e de plataforma. Relaciona o processo de capitalismo digital com a dataficação e analisa as noções de imperialismo de plataforma, colonialismo digital e de dados. Por fim, mostra as relações de subordinação tecnológica que reproduzem o capital, impulsionadas pela doutrina neoliberal, que bloqueiam a inventividade e a criatividade tecnológica locais.

Palavras-chave: Colonialismo digital. Colonialismo de dados. Plataformização. Capitalismo digital. Países tecnologicamente empobrecidos.

\section{Abstract}

The objective of this text is to characterize the intense digitization scenario and its relationship with capitalism. It discusses the definitions of informational, digital, data-based, surveillance and platform capitalism. It relates the process of digital capitalism to datafication and analyzes the notions of platform imperialism, digital and data colonialism. Finally, it shows the technological subordination relations that reproduce capital, driven by the neoliberal doctrine, which block local technological inventiveness and creativity.

Keywords: Digital colonialism. Colonialism date. Platformization. Digital capitalism. Technologically impoverished countries.

\section{Resumen}

El objetivo de este texto es caracterizar el escenario de intensa digitalización y su relación con el capitalismo. Analiza las definiciones de capitalismo informativo, digital, basado en datos, de vigilancia y de plataforma. Relaciona el proceso del capitalismo digital con la datificación y analiza las nociones de imperialismo de plataforma, colonialismo digital y de datos. Finalmente, muestra las relaciones de subordinación tecnológica que reproducen el capital, impulsadas por la doctrina neoliberal, que bloquean la inventiva y creatividad tecnológica local.

Palabras clave: Colonialismo digital. Colonialismo de datos. Plataformatización. Capitalismo digital. Países tecnológicamente empobrecidos.

A importância de caracterizar o momento que vivemos é semelhante ao desenho de um mapa. Como toda tentativa de representação da realidade, podemos fazê-la com maior ou menor precisão, considerando diversos níveis ou achatando os relevos, enfim podemos detalhar as conexões das várias trilhas ou simplesmente registrarmos apenas os caminhos mais longos e largos. Ao definirmos conceitos, estamos demarcando o que iremos olhar, não somente o que iremos relatar. Assim, podemos observar a comunicação e as tecnologias a partir de aparatos conceituais que as aproximam ou as isolam artificialmente da sociedade em fluxo e de suas instituições. Isso gera um conjunto conceitual que disciplina os olhares. 
Este artigo busca olhar as conexões entre as tecnologias digitais e as operações do capital, uma vez que não podemos desconsiderá-lo, seja na formatação dos objetos digitais e suas infraestruturas, nas delimitações de seus usos, na construção de tendências do desenvolvimento tecnológico. Especificamente, aqui será problematizada a chamada Inteligência Artificial (IA) que organiza as plataformas digitais e grande parte das operações atuais envolvendo as redes informacionais e os principais serviços que nelas operam.

Em um texto lançado em 2019 sob o título "Inhuman Power", a partir da perspectiva marxista, Dyer-Witheford, Kjosen e Steinhoff apresentaram a IA como uma espécie de arma do capital para aprofundar a expropriação de riquezas, submetendo a humanidade à condição de trans-humanos expropriados. Alertam para a ilusão de que a adoção generalizada da IA poderia levar à superação das desigualdades e do capitalismo. Indicam para um sentido contrário e denunciam o risco da consolidação

Shoshana Zuboff

cunhou a expressão capitalismo de vigilância para caracterizar "uma nova ordem econômica que reivindica a experiência humana como matéria-prima gratuita para práticas comerciais dissimuladas de extração, previsão e vendas". de um capitalismo que prescinde dos humanos para a reprodução do seu processo de acumulação.

Explorando uma perspectiva teórica distinta, a pesquisadora Shoshana Zuboff cunhou a expressão capitalismo de vigilância para caracterizar "uma nova ordem econômica que reivindica a experiência humana como matéria-prima gratuita para práticas comerciais dissimuladas de extração, previsão e vendas". O capitalismo estaria lançando as tecnologias informacionais para a formação de uma economia da vigilância que busca impor uma "ordem coletiva baseada na certeza total". A conversão dos fluxos da vida em dados e seu tratamento por modelos de extração de padrões comportamentais e de predição vão reforçar a importância das tecnologias de IA.

Os processos descritos por Zuboff são empiricamente constatáveis. Todavia, a caracterização da vigilância como a essência ou o elemento definidor do capitalismo não parece ser a mais abrangente. $\mathrm{O}$ capitalismo continua sendo baseado na extração de mais-valia. Diferente do século XIX, essa extração não está limitada apenas ao interior da fábrica. Nem a fábrica continua sendo o centro principal de geração de valor do atual capitalismo. Daí já há algum tempo, uma série de teóricos terem empregado outros termos para demonstrar que o capitalismo não seria principalmente industrial, mas informacional (LOJKINE, 1995; CASTELLS, 1999; PEREZ, 2010). Isso significa que os produtos de maior valor e as tecnologias de maior complexidade e centralidade seriam tecnologias de informação.

Apesar de óbvio é preciso que seja dito que economia informacional, ao superar a economia industrial, não implicou a supressão da indústria. Assim como o mundo industrial não eliminou a agricultura, afirmar que o capitalismo é informacional não resulta no fim do 
uso ou da necessidade de produtos industriais, assim como a revolução industrial não gerou o fim de produtos agrícolas. O capitalismo não é só material, é também imaterial (GORZ, 2005). Constatar o capitalismo que gera valores com bens intangíveis também não implica que os objetos e serviços digitais não requeiram complexas e muitas vezes gigantescas infraestruturas físicas. A própria internet, uma rede de camadas lógicas, não poderia existir sem sua camada física. Entretanto, não parece correto sustentar que a Internet é igual à velha atividade de telefonia, pois ambas dependeriam de cabos e conexões de telecomunicação.

O capitalismo sem dúvida alguma se tornou informacional. As grandes indústrias são operadas por tecnologias informacionais. A agricultura, ou melhor, o agronegócio está sendo afetado profundamente pelas tecnologias digitais. A base dessas tecnologias é cibernética, ou seja, as tecnologias de informação se desenvolveram sobre os primados da ciência cibernética que é o estudo científico do "controle e comunicação em animais e máquinas" (WIENER, 2019). As tecnologias cibernéticas, por sua vez, se desenvolveram a partir de informações expressas em sequências de símbolos discretos chamados dígitos. Os dados digitais se consolidaram em dígitos binários, ou bits, expressos em ausência ou presença, em zero ou um.

A cibernética avançou pelo caminho digital. Ela permitiu estruturar uma rede de comunicação e controle jamais vista, a Internet. A tecnologia cibernética permite interagir e controlar ao mesmo tempo. Também assegura que possamos observar e vigiar as conexões realizadas, uma vez que rastros digitais vão deixando suas marcas nos dispositivos da rede. Mais do que simplesmente vigiar, as tecnologias digitais baseadas na cibernética são tecnologias de controle. Com uma inigualável qualidade sintética, Alexander Galloway introduz o livro Protocol: how control exists after decentralization, com o seguinte parágrafo:

Este livro é sobre um diagrama, uma tecnologia e um estilo de gerenciamento. O diagrama é a rede distribuída, uma forma estrutural sem centro que se assemelha a uma teia ou malha. A tecnologia é o computador digital, uma máquina abstrata capaz de realizar o trabalho de qualquer outra máquina (desde que possa ser descrita logicamente). O estilo de gerenciamento é o protocolo, o princípio de organização nativo para computadores em redes distribuídas. Os três se unem para definir um novo aparato de controle que ganhou importância no início do novo milênio. ${ }^{1}$ (GALLOWAY, 2004, p. 3).

Enquanto Galloway pensou a expansão das redes a partir da influência de Foucault e Deleuze, Dan Schiller descreveu a digitalização sob a perspectiva da economia política, mostrando que ela se deu sob influência da lógica expansionista que incitava a desregulamentação de mercados e cultuava a redução da ação direta do Estado na atividade econô-

1 Tradução livre: This book is about a diagram, a technology, and a management style. The diagram is the distributed network, a structural form without center that resembles a web or meshwork.The technology is the digital computer, an abstract machine able to perform the work of any other machine (provided it can be described logically). The management style is protocol, the principle of organization native to computers in distributed networks. All three come together to define a new apparatus of control that has achieved importance at the start of the new millennium. (GALLOWAY, 2004, p. 3). 
mica. O capitalismo digital se expandiu com a Internet e foi embalado pelo ordenamento neoliberal do planeta. O rápido crescimento da Internet gerou uma inversão no ecossistema comunicacional. A economia da comunicação baseada na difusão foi suplantada pela economia da atenção. Na Internet, o difícil não é falar, mas ser ouvido.

O sucesso da produção distribuída de conteúdos nas redes digitais estabilizou e expandiu negócios baseados na captura do trabalho criativo de milhares de pessoas pelo planeta. Grupos capitalistas logo perceberam o sucesso das práticas colaborativas e da inventividade em rede. Trataram de privatizar e extrair valor da captura dessas práticas. Assim, surgiram os modelos de negócios baseados na entrega de interfaces e serviços gratuitos para a postagem de conteúdos dos usuários. Com isso, os donos das interfaces podiam concentrar as atenções e conquistar a permanência dos usuários nas suas infraestruturas.

As plataformas estão em um conjunto de atividades de grande relevância cultural, cotidiana e econômica.
O avanço do poder computacional e da capacidade de armazenamento de dados viabilizou não somente a coleta de conteúdos não pagos aos seus criadores, mas também a coleta de dados de todos os usuários dos serviços e interfaces. Esses dados permitiram extrair padrões de comportamentos on-line, mas viabilizaram a explosão dos sistemas algorítmicos de classificação, segmentação de públicos e de predição de atitudes e interesses. Expressões como

Big Data, mineração de dados, computação em nuvem emergiram em meados da primeira década do século XXI, junto com o retorno da chamada Inteligência Artificial.

Enquanto o capitalismo mergulhava na crise especulativa de 2008, os negócios baseados em coleta e tratamento de dados coletados de usuários de serviços gratuitos avançava e prometia grande lucratividade. O sucesso do modelo Google - entregar serviços gratuitos em troca de dados pessoais - influenciou o capitalismo financeiro e um conjunto de segmentos econômicos que passaram a adotá-los. Nesse período, o capital também desfechou um ataque fulminante às comunidades de software livre que desenvolviam soluções tecnológicas com base na solidariedade e no compartilhamento do conhecimento técnico, permitindo que muitos ganhassem com o trabalho de adequação, implementação e suporte dessas soluções. Diversos desenvolvedores foram cooptados, muitos códigos desenvolvidos coletivamente foram apropriados privadamente. Mas o modelo livre foi convertido em modelo aberto. $O$ patenteamento avançou na área digital e empresas focadas na web passaram a liderar a lista de maiores detentores de patentes.

Já no início da segunda década do século XXI, a comunicação em redes digitais havia se tornado hegemônica. Outro fato fundamental é que as redes sociais passaram a comandar a audiência da internet. O mecanismo de busca do Google, o YouTube, Facebook lideram, desde o início do século XXI, o ranking de sítios mais visitados da rede. Os capitais migraram para as plataformas de dados. Isso reforçou a aposta das plataformas e grandes corporações nas tecnologias de IA baseadas em dados. 
Essa longa exposição inicial tem como objetivo demonstrar que o ordenamento neoliberal se expandiu no mesmo período que as tecnologias informacionais. O neoliberalismo influenciou os rumos adotados no desenvolvimento dessas tecnologias digitais? Muito provavelmente sim. Todavia, se podemos constatar correlações, a construção de causalidades requer uma pesquisa mais aprofundada. Com a expansão da internet e da digitalização, algumas corporações, tal como o Google, apostaram no modelo de negócios baseados no tratamento de dados pessoais para sua posterior organização em amostras de perfis microssegmentados que têm o acesso vendido a quem quer atingi-los com a oferta de conteúdos e serviços. Esse modelo reorientou os negócios digitais para uma economia de dados. Por isso, nomear o capitalismo digital de capitalismo digital baseado em dados parece caracterizar com maior precisão e abrangência o momento que vivemos.

\section{Plataformização}

O pesquisador Nick Srnicek (2017) chamou o estágio econômico atual de capitalismo de capitalismo de plataforma. Sua ênfase é no tipo de estrutura empresarial que mais aproveitou a economia digital centrada em dados. As plataformas são estruturas voltadas à interação nas redes digitais que buscam reunir os agentes principais de uma atividade social ou de um mercado. As plataformas criam interfaces digitais reunindo a oferta e a demanda de determinado serviço ou segmento de mercado. Com o tempo, a plataforma acumula dados de quem oferece um produto e de quem o procura. Sua posição de intermediária vai permitindo à plataforma se tornar mediadora daquele segmento do mercado.

As plataformas estão em um conjunto de atividades de grande relevância cultural, cotidiana e econômica. São estruturas gerenciais e comunicativas por excelência, não importa o ramo em que atuem. O mecanismo de busca do Google é um tipo bem-sucedido de plataforma. Ele rastreou a oferta de conteúdos na Internet e os disponibilizou para quem precisava encontrá-los. Assim, reuniu informações valiosas do lado da oferta e do lado da demanda. Mas, longe da autoproclamada neutralidade, o Google organiza a entrega dos conteúdos buscados seguindo critérios de relevância para o demandante, mesclados ao interesse de anunciantes que compraram o acesso a determinados públicos que buscavam determinada palavra-chave, frase ou assunto.

O Facebook é uma plataforma de relacionamento on-line que se autodenomina rede social on-line. O conteúdo postado na plataforma é feito por seus usuários. A mediação da plataforma se dá principalmente com a modulação do olhar. Os conteúdos que aparecem na nossa timeline, espécie de mural de textos e imagens postadas pelos demais usuários da rede, são aqueles que o sistema algorítmico da plataforma definiu. Portanto, o Facebook controla nosso olhar, nos incentiva a ler, ver e ouvir determinados tópicos e materiais digitais. Os algoritmos encurtam a realidade e tentam nos conduzir e incentivar nossas ações pelos links digitais. Plataformas realizam sua mediação por modulação dos comportamentos on-line.

Existem plataformas de variados tamanhos. Mas há um indiscutível processo de oligopolização econômica e cultural em escala global que está concentrando os fluxos de atenção 
em gigantescas plataformas. Essa é uma dinâmica notável do atual capitalismo baseado em dados. A plataformização está penetrando diversos mercados. A Amazon não é uma mera loja virtual. É uma plataforma de comércio eletrônico, um market place. Diversas empresas começam a obter uma grande parte de suas vendas pela plataforma da Amazon. A interação dos compradores é com a Amazon e esta indica as regras segundo as quais o fornecedor deve entregar o produto ao comprador. Com isso, a Amazon reforça os fluxos de atenção em seu site, aumenta a velocidade de entrega, constrói infraestruturas físicas ao redor das grandes cidades e vai concentrando a intermediação digital de comércio, derrotando os médios e pequenos comerciantes digitais e não digitais locais.

O Uber se consolida como a grande plataforma de

O Uber se consolida como a grande plataforma de transporte individual porque consegue ter os dados de milhares de motoristas e de milhões de passageiros potenciais que possuem seu aplicativo instalado. transporte individual porque consegue ter os dados de milhares de motoristas e de milhões de passageiros potenciais que possuem seu aplicativo instalado. Sem se responsabilizar por nenhum custo dos motoristas, sem pagar quaisquer direitos trabalhistas, os colocam na condição de usuários de uma plataforma. Eles devem uma série de obrigações em troca de da obtenção de corridas remuneradas. Além de controlar o sistema de pagamentos do motorista, o Uber fica com um alto percentual de cada corrida. Caso seja atacado por uma plataforma concorrente em determinadas cidades, o Uber pode lançar promoções e facilidades tanto aos motoristas quanto aos passageiros, pode ofertar corridas grátis e aumentar a remuneração de motoristas.

Os gestores do Uber sabem exatamente quantas corridas seu aplicativo está gerando em um exato momento em qualquer localidade do planeta. Sabe se está ocorrendo queda da oferta de veículos em virtude do aumento da gasolina ou outra causa. A plataforma pode interferir e baixar seu percentual por corrida durante meses, se necessário. Sem relações contratuais trabalhistas e com gigantescos aportes de capitais obtidos de investidores dos países ricos, o Uber tenta expandir seu modelo neoliberal de converter trabalhadores em empresas de um único dono que é, concomitantemente, seu único funcionário. Assim, o capitalismo dirigido pela doutrina neoliberal encontra seu melhor modelo, o trabalhador precarizado e chamado de empreendedor de si.

A Microsoft era uma empresa de software proprietário que obtinha seu faturamento principalmente da venda de licenças de uso de seus programas para empresas privadas e instituições públicas. Apesar de seu discurso contra a "pirataria", o uso de softwares não licenciados pelos usuários residenciais não abalava sua lucratividade, em vez disso, gerava uma massa de usuários treinados sem custo para as empresas, o que reforçava a ideia de que o seu software era superior e intuitivo. Na realidade, o Windows era repleto de falhas e muito pouco intuitivo. Durante muito tempo, para desligar o computador o usuário tinha 
de ir no botão "iniciar". Isso era visto como "natural", devido ao processo de treinamento generalizado que as pessoas tinham quando iam utilizar um computador pela primeira vez. A Microsoft percebeu o processo de plataformização em curso e buscou se tornar uma plataforma de múltiplos serviços e produtos.

Com produtos e serviços que vão de clientes pessoais aos serviços de nuvem, a Microsoft tenta competir com as gigantes Google, Apple, Amazon e Facebook. A maior aquisição da Microsoft até hoje foi o Linkedin, rede de relacionamentos profissionais. A compra ocorreu em junho de 2016 por US\$26,2 bilhões. Em abril de 2021, a Microsoft adquiriu a maior empresa de inteligência artificial da área de Saúde, a Nuance, por US\$19,7 bilhões. A antiga empresa de software quer se tornar uma plataforma múltipla capaz de concorrer com os demais gigantes e conseguir se manter diante do crescimento das plataformas chinesas Baidu, Alibaba, Tencent, Huawei. Uma das áreas de maior avanço da Microsoft é na mediação educacional (Microsoft Teams) e no agronegócio, com a Azure FarmBeats. O procedimento básico é o mesmo das demais plataformas: obter dados de todos envolvidos na atividade e passar a mediar as interações e a modular as opções e atitudes seja da oferta seja da demanda.

\section{Imperialismo de plataforma e colonialismo digital}

Dal Yong Jin, pesquisador coreano e professor da Escola de Comunicação da Simon Fraser University, no Canadá, defende que emergiu um novo tipo de imperialismo, nomeado de imperialismo de plataforma (JIN, 2013). Podemos definir o imperialismo como uma fase do capitalismo a partir do último quarto do século XIX e que pode ser caracterizado pela grande concentração do capital em torno de monopólios, a eclosão do capital financeiro com a fusão dos capitais bancário e industrial, a exportação de capitais com peso igual ou superior à exportação de mercadorias e a divisão do mundo entre as potências capitalistas (LENIN, 2003).

Para detalhar a dinâmica imperialista, Jin recupera a descrição do conceito pensada pelo teórico e líder revolucionário russo Vladimir Ilyich Ulianov, conhecido como Lenin. No texto,

"Imperialismo: Etapa Superior do Capitalismo", Lenin argumenta que, na fase imperialista, os capitalistas produziriam mercadorias e extrairiam matérias-primas a baixo custo nos países periféricos e colonizados, além de criar nessas áreas de exploração uma classe dominante submissa que consumiria importados caros e bloquearia a expansão das indústrias locais.

A ascensão global das plataformas e sua posição de intermediárias estratégica entre diversos segmentos econômicos, bem como a imposição e o controle da propriedade intelectual consolidaram uma posição cultural e econômica tão ou mais profunda do que as antigas corporações transnacionais do mundo industrial. Jin argumenta que, já na década de 1970, Schiller havia identificado a supremacia dos Estados Unidos e de algumas nações europeias no domínio da criação e distribuição de produtos midiáticos como um componente funda- 
mental do imperialismo ocidental e nomeando-o de imperialismo cultural (JIN, 2013, p. 149).

Considerando plataformas como intermediárias de mídia digital, a ideia de imperialismo de plataforma se refere a uma relação assimétrica de interdependência entre o Ocidente, principalmente os EUA, e os demais países do planeta. As plataformas reforçam os fluxos de capitais para alguns poucos países, com destaque para a predominância das plataformas norte-americanas. Além disso, Jin aponta que as plataformas amplificam o poder econômico desses países, a partir da exportação de serviços digitais e pela expansão da propriedade intelectual, em especial, a norte-americana.

(2)

A expressão cibercolônia aqui se refere à condiç̧ão de atraso tecnológico em relação à vanguarda sinoamericana no caso da IA que é, atualmente, um conjunto de tecnologias dependentes de dados.

Os pesquisadores Nick Couldry e Ulises Mejias utilizaram a expressão colonialismo de dados para caracterizar esse momento de conversão dos fluxos da vida em uma torrente de dados, abrindo um período de uma nova fase de acumulação do capital. Assim, o colonialismo de dados seria tão relevante para o capitalismo na atualidade como foi o colonialismo histórico para a expansão do capitalismo mercantil europeu e sua transição para o capitalismo industrial. As grandes corporações de tecnologia estariam no comando desse processo de extração e concentração de dados em todo o planeta (COULDRY; MEJIAS, 2020).

Definido de forma mais explícita, colonialismo de dados é o nosso termo para a extensão de um processo global de extração que começou sob o colonialismo e continuou através do capitalismo industrial, culminando na nova forma de hoje: em vez de recursos naturais e trabalho, o que agora está sendo apropriado é a vida humana por meio de sua conversão em dados. O resultado degrada a vida, primeiro por expô-la continuamente ao monitoramento e vigilância (por meio da qual os dados são extraídos) e, segundo, por tornar a vida humana um insumo direto para a produção capitalista. O colonialismo de dados é, em outras palavras, uma emergente ordem de apropriação e extração de recursos sociais com fins lucrativos por meio de dados, praticada via relacionamento de dados. ${ }^{2}$ (COULDRY; MEJIAS, 2019, p. xix).

É inegável que as plataformas e as diversas empresas da economia digital-dataficada coletam dados em todos os territórios onde atuam. Atuam coletando dados das po-

2 Tradução Livre: More explicitly defined, data colonialism is our term for the extension of a global process of extraction that started under colonialism and continued through industrial capitalism, culminating in today's new form: instead of natural resources and labor, what is now being appropriated is human life through its conversion into data. Th e result degrades life, first by exposing it continuously to monitoring and surveillance (through which data is extracted) and second by thus making human life a direct input to capitalist production. Data colonialism is, in other words, an emerging order for appropriating and extracting social resources for profit through data, practiced via data relations. 
pulações de todo o planeta. Contudo, aqui apresentamos uma forte objeção à tese de um colonialismo que desconsidera efetivamente as assimetrias entre as sociedades. Os efeitos da extração e do tratamento massivo de dados não são os mesmos na Europa e no Brasil. Dados extraídos dos países tecnologicamente pobres alimentam os sistemas algorítmicos das corporações, principalmente as plataformas, de um seleto grupo de países ricos. Os fluxos de dados extraídos nunca são dos Estados Unidos ou Europa para o Brasil nem para a Argentina. São sempre em uma única direção: do sul para o norte.

No Relatório sobre a Inteligência Artificial (IA) na França, coordenado pelo matemático Cedric Villani, intitulado For a meaningful artificial intelligence, vemos um alerta: "os Estados Unidos e a China estão na vanguarda dessa tecnologia [de IA] e seus investimentos excedem em muito os feitos na Europa. [... Tendo em vista que a França e a Europa já podem ser consideradas 'cibercolônias' em muitos aspectos, é essencial que resistam a todas as formas de determinismo, propondo uma resposta coordenada a nível europeu” (VILLANI et al., 2018). A expressão cibercolônia aqui se refere à condição de atraso tecnológico em relação à vanguarda sino-americana no caso da IA que é, atualmente, um conjunto de tecnologias dependentes de dados. Todavia, a situação tecnológica da Europa está bem distante da precariedade da América do Sul e África.

Michael Kwet utiliza o conceito de colonialismo digital e o definiu como "o uso da tecnologia digital para a dominação política, econômica e social de outra nação ou território”. Trata-se de uma perspectiva mais abrangente que a oferecida pelo colonialismo de dados, uma vez que considera todo o conjunto de tecnologias utilizadas para os processos de digitalização e dataficação.

De forma mais ampla, o colonialismo digital é da consolidação de uma divisão desigual de trabalho, onde os poderes dominantes fizeram uso das suas propriedades de infraestrutura digital, conhecimento e controle dos meios de computação para manter o Sul em uma situação de dependência permanente. Essa divisão desigual do trabalho evoluiu. Economicamente, a manufatura caiu na hierarquia de valor, e foi substituída por uma economia de alta tecnologia avançada, em cujo comando as firmas de big tech estão firmemente instaladas. (KWET, 2021).

Apesar de os dados serem um ativo de grande valor econômico, de serem indispensáveis para alimentar as redes neurais, o deep learning, as infraestruturas necessárias ao seu armazenamento, processamento e tratamento são indispensáveis e estão concentradas nas grandes plataformas dos países ricos.

\section{0 controle do fluxos de dados e as infraestruturas do digital}

Há uma sutil combinação entre as condutas neoliberais e as práticas do colonialismo digital que viabilizam a extração massiva de dados das populações dos países tecnologicamente pobres. O caso do aplicativo do governo federal brasileiro chamado SouGov é eluci- 
dativo. Lançado na gestão de Paulo Guedes no Ministério da Economia, o aplicativo visa a concentrar as interações de um milhão de servidores e pensionistas, civis e militares, com o sistema de gestão de pessoas da administração pública federal.

Nos termos de uso e política de privacidade, documentos exigidos pela Lei Geral de Proteção de Dados (LGPD), o governo descreve a seguinte operação no item Tratamento Internacional de Dados:

No cenário atual, em que

os dados são valiosos e

estratégicos, o governo

federal brasileiro

reforça sua condição de

usuário subordinado.

Entrega os dados para

o treinamento e a

modelagem algorítmica

de uma empresa privada

estrangeira.
SouGov utiliza a solução de central de ajuda (chat), denominada SerproBot, que utiliza tecnologia da empresa IBM - International Business Machines. Nesse contexto, o usuário fica ciente de que os dados digitados no chat poderão ser transferidos internacionalmente e ficam armazenados na infraestrutura da empresa por um período de 30 (trinta) dias. Após este período os dados são excluídos em definitivo. Tal armazenamento tem o objetivo de prover o aprendizado de máquina da ferramenta de chat denominada "Watson", onde as interações dos usuários no chat são utilizadas para "aprendizado" pelo computador que envia as respostas automáticas quando o usuário está sendo atendido por meio do chat do serviço SouGov. (BRASIL, 2021).

Os dados das interações dos servidores federais com o aplicativo vão alimentar os sistemas algorítmicos da empresa privada hospedada nos Estados Unidos, país sem legislação compatível com a LGPD

brasileira. Desse modo, as perguntas e dúvidas, o modo de escrever e de digitar dos servidores brasileiros serão utilizados para "prover o aprendizado de máquina" dos algoritmos da IBM, empresa norte-americana fornecedora de soluções e consultorias em tecnologias informacionais para o Brasil.

No cenário atual, em que os dados são valiosos e estratégicos, o governo federal brasileiro reforça sua condição de usuário subordinado. Entrega os dados para o treinamento e a modelagem algorítmica de uma empresa privada estrangeira. Isso denota que os dirigentes do Ministério da Economia consideram que nenhuma empresa ou universidade brasileira seria capaz de entregar um serviço automatizado, um chatbot, capaz de responder às indagações dos servidores que escrevem em língua portuguesa.

Chama a atenção o fato de o governo afirmar em seu termo de uso que os dados das interações do servidor brasileiro com a IBM serão destruídos após 30 dias. Essa afirmação esconde uma questão decisiva. Os chamados algoritmos de aprendizado de máquina se baseiam na extração de padrões e classificação dos dados para a formação de modelos. $\mathrm{O}$ dado pode ser eliminado, mas o modelo ficará com a IBM e não com o governo brasileiro. 
Isso implica uma dependência da gestão pública brasileira da empresa norte-americana, ou o treinamento de outros sistemas algorítmicos em outros sistemas algorítmicos que provavelmente utilizarão outro hardware.

A inteligência artificial que mais avançou a partir de meados da primeira década do século XXI é baseada em dados. Ela depende de uma grande quantidade de dados para que seus algoritmos criem modelos chamados inteligentes. Essa inteligência artificial por tal motivo é chamada de aprendizado de máquina e emprega uma diversidade de técnicas distintas, como o aprendizado profundo, entre outras. Isso implica uma fusão da modelagem estatística com o alto processamento computacional e uma gigantesca quantidade de dados para o aperfeiçoamento dos sistemas algorítmicos.

Países são empobrecidos tecnologicamente toda vez que os dados de suas populações são extraídos para alimentar os algoritmos das grandes corporações dos países ricos, em geral, plataformas digitais. Essa extração gera valor para as empresas que, por sua vez, vendem para os países empobrecidos produtos e serviços de inteligência artificial criados a partir dos dados deles extraídos. Esse processo priva e bloqueia o desenvolvimento da inteligência coletiva local e transforma os países tecnologicamente empobrecidos em eternos consumidores e usuários.

Além de problemas econômicos para sustentar com produtos agrícolas e industriais de baixa complexidade a compra de produtos e serviços criados a partir da inteligência artificial, temos a consolidação das assimetrias tecnológicas que vão implicar a obstrução e a ausência da perspectiva cultural dos povos do Sul no desenvolvimento, na invenção e na criação das tecnologias digitais. É inegável que as tecnologias guardam traços de seus criadores e das culturas onde foram gestadas. A ideia de diversidade cultural deve ser observada quando falamos de tecnologias.

A crença em uma universalidade neutra, acima das culturas e de distintos processos históricos, pode ser vista como a grande operadora da mentalidade subordinada ou submetida à colonialidade (QUIJANO, 2005). Ela reproduz as condições de inviabilidade e bloqueio dos processos inventivos locais e aprofunda o epistemicídio das cosmovisões dissemelhantes e desconformes com as originadas do colonizador branco europeu, hoje, mais representadas no poderio estadounidense. Como exemplos dessa conduta, o gestor público, envolvido pela doutrina neoliberal afirma que utilizará as tecnologias mais baratas e de maior qualidade. Nada mais razoável e, simultaneamente, mais destrutivo das possibilidades de inventividade tecnológica local.

\section{Conclusão: neoliberalismo como desarticulador criativo}

Com preços mais baixos, com serviços aprimorados pelos dados coletados em todo o planeta, com gigantescas e disponíveis infraestruturas digitais, as grandes corporações e plataformas dos países tecnologicamente ricos vão desarticulando as possibilidades de os demais países construírem bases e suportes capazes de criar soluções novas e culturalmente diversas, úteis aos seus territórios e populações. 
Assim, os países aprofundam sua condição de comprador e usuário de produtos e serviços de IA criados pelas gigantescas plataformas, mantidos em grande aperfeiçoamento gerado pela constante extração de dados dos países inventivamente bloqueados e empobrecidos. Esse processo conta não somente com o lobby e com a força econômica da plataforma colonizadora, mas com a adesão das classes dominantes locais, ávidas por utilizarem a melhor tecnologia do momento e completamente embevecidas pelo ordenamento neoliberal e pelo profundo desprezo para com a criatividade e inventividade de sua população.

\section{Referências bibliográficas}

BRASIL. GOV.BR. Giverno Federal. Termo de Uso e Política de Privacidade Sou Gov.br. 28 abr. 2021. Disponível: https://www.gov.br/servidor/pt-br/assuntos/sou-gov.br/termo-de-uso-e-politica-de-privacitade-sougov.br. Acesso em: 14 out. 2021.

CASTELLS, Manuel. Era da Informação: Economia, Sociedade e Cultura - A Sociedade em Rede. São Paulo: Paz e Terra, 1999.

COULDRY, Nick; MEJIAS, Ulises A. The Costs of Connection: How Data Are Colonizing Human Life and Appropriating It for Capitalism. Stanford University Press, 2020.

DYER-WITHEFORD, Nick; KJØSEN, Atle Mikkola; STEINHOFF, James. Inhuman power. Artificial intelligence and the future of capitalism. London: Pluto Press, 2019.

GALLOWAY, Alexander R. Protocol: How control exists after decentralization. MIT press, 2004.

GORZ, André. Imaterial (o)-Conhecimento, Valor. Annablume, 2005.

JIN, D. Y. The construction of platform imperialism in the globalization era. Communication, Capitalism \& Critique. Open Access Journal for a Global Sustainable Information Society. v. 11, n. 1, p. 145-172, 2013.

KWET, Michael. A ameaça nada sutil do Colonialismo Digital. Outras Palavras, 15 mar. 2021. Disponível em: https://outraspalavras.net/tecnologiaemdisputa/a-ameaca-nada-sutil-do-colonialismo-digital/. Acesso em: 6 ago. 2021.

LENIN, V. I. O Imperialismo. Fase Superior do Capitalismo. Centauro, 2003.

LOJKINE, Jean. A revolução informacional. São Paulo: Cortez, 1995.

PEREZ, Carlota. Technological revolutions and techno-economic paradigms. Cambridge Journal of Economics, v. 34, n. 1, p. 185-202, 2010.

QUIJANO, Aníbal. A colonialidade do saber: eurocentrismo e ciências sociais. Perspectivas latino-americanas. Buenos Aires: CLACSO, p. 117-142, 2005.

SCHILLER, Dan. Digital capitalism: Networking the global market system. MIT press, 1999. 
SRNICEK, Nick. Platform capitalism. John Wiley \& Sons, 2017.

VAN DIJCK, José. Datafication, dataism and dataveillance: Big Data between scientific paradigm and ideology. Surveillance \& Society, v. 12, n. 2, p. 197-208, 2014.

VILLANI, C.; BONNET, Y.; RONDEPIERRE, B. For a meaningful artificial intelligence: Towards a French and European strategy. Conseil National du Numérique, 2018.

WIENER, Norbert. Cybernetics or Control and Communication in the Animal and the Machine. MIT press, 2019.

ZUBOFF, Shoshana. A era do capitalismo de vigilância. Rio de Janeiro: Intrinseca, 2021.

Data do recebimento: 26/10/2021

Data do aceite: 01/11/2021

Dados do autor:

Sérgio Amadeu da Silveira

http://lattes.cnpq.br/6800442072685268

Doutor em Ciência Política e professor associado da UFABC. Bolsista CNPq de Produtividade em Pesquisa 2. 